\title{
Penanaman Nilai-nilai Semangat Kebangsaan dalam menumbuhkan semangat Revolusi Mental Mahasiswa
}

\author{
Warsito \\ STAB Negeri Sriwijaya Tangerang banten \\ saatakudisini@yahoo.co.id
}

\begin{abstract}
ABSTRAK
Revolusi (dari bahasa latin revolutio, yang berarti "berputar arah") adalah perubahan fundamental (mendasar) dalam struktur kekuatan atau organisasi yang terjadi dalam periode waktu yang relatif singkat. Mental atau tepatnya Mentalitas adalah cara berpikir atau kemampuan untuk berpikir, belajar dan merespons terhadap suatu situasi atau kondisi. Revolusi Mental dapat diartikan dengan perubahan yang relatif cepat dalam cara berpikir kita dalam merespon, bertindak dan bekerja.

Makalah ini membahas penanaman nilai-nilai semangat kebangsaan di tengah krisisnya ideologi dan budaya bangsa. Penulis menggunakan metode penelitian kualitatif dengan data kepustakaan sebagai sumber utama penelitian ini. Penulis menggunakan studi dalam konteks penanaman nilai-nilai wawasan kebangsan dalam menumbuhkan semangat revolusi mental mahasiswa sehingga dapat membentuk generasi muda bangsa yang berkarakter dengan semangat menjunjung tinggi nilai-nilai kebudayaan dan moralitas bangsa. Dalam penyusunan makalah ini, penulis menggunakan mahasiswa sebagai objek utama konsep penanaman nilai wawasan kebangsaan. Oleh sebab itu, dalam penulisannya penulis menggunakan pendekatan strategi penanaman nilai-nilai revolusi mental melalui mata kuliah pendidikan kewarganegaraan. Melalui pendekatan pendidikan kewarganegaraan diharapkan mahasiswa dapat menumbuhkan semangat dan kesadaran dalam menjunjung tinggi dan mengembangkan karakter manusia yang unggul dan bermoral serta menjaga nilai-nilai kebudayaan menuju perubahan bangsa yang berdaulat, mandiri dan berdaulat.
\end{abstract}

Keyword: Penanaman, Nilai-nilai, wawasan kebangsaan, revolusi mental, mahasiswa

\section{ABSTRACK}


Keyword: Planting, values, national awareness, mental revolution, student

Revolution (from the Latin revolutio, which means "turn around") is a fundamental change (fundamental) in the power structure or organization that occur in a relatively short period of time. Mental or rather the mentality is a way of thinking or the ability to think, learn and respond to a situation or condition.

Mental revolution can be interpreted with a relatively rapid change in our way of thinking to respond, act and work.

This paper discusses the cultivation of the values of the national spirit in the midst of a crisis of ideology and culture. The author uses qualitative research methods with literature data as the main source of this study. The author uses the study in the context of value investment kebangsan insight into foster the spirit of student mental revolution so as to form the character of the young generation in the spirit of upholding the values of culture and morality. In preparing this paper, the authors use the students as the main object of value investment concept of national awareness. Therefore, in writing authors use the approach of value investment strategies mental revolution through civic education courses. Through education of students are expected to foster civic spirit and awareness in upholding and developing excellent human character and morality as well as maintaining the cultural values towards changes in a sovereign nation, independent and sovereign.

\section{A. Pendahuluan}

Revolusi mental merupakan agenda prioritas pemerintahan Indonesia saat ini. Revolusi mental merupakan revolusi karakter bangsa yang dilakukan melalui proses pendidikan. Revolusi 
mental adalah gerakan seluruh rakyat Indonsia bersama pemerintah untuk memperbaiki karakter bangsa menjadi yang lebih baik (revolusi mental.go.id). Hal ini dapat dilihat dari point 8 Nawacita yang berbunyi : "Melakukan revolusi karakter bangsa melalui kebijakan penataan kembali kurikulum pendidikan nasional dengan mengedepankan aspek pendidikan kewarganegaraan, yang menempatkan secara proporsional aspek pendidikan, seperti pengajaran sejarah pembentukan bangsa, nilai-nilai patriotisme dan cinta Tanah Air, semangat bela negara dan budi pekerti di dalam kurikulum pendidikan Indonesia”.

Revolusi mental sendiri telah digelorakan oleh Bung Karno sejak tahun 1957 dan kemudian dihidupkan kembali oleh pemerintahan Jokowi-JK dalam bingkai konsepsi trisakti (berdaulat secara politik, mandiri secara ekonomi, dan berkepribadian secara kebudayaan). Revolusi mental memfokuskan pada perubahan karakter, moralitas, pola pikir, bangsa Indonesia untuk kembali ke jati diri bangsa yang berdaulat, berdikari dan berkeperibadian, di tengah arus globalisasi. Revolusi mental dalam pembelajaran (Mulyasa, 2015) revolusi mental harus dijadikan landasan pembangunan pendidikan agar dapat menimbulkan kesadaran dan mengikat para pejabat dalam sistem pendidikan pada tingkat nasional dan daerah sehingga menghasilkan kebijakan dan melaksanakan kebijakan secara berkesinambungan.

Ada beberapa alasan yang melatarbelakangi mengapa mahasiswa memerlukan revolusi mental yakni:

\section{Aspek Ideologi,}

Mahasiswa Indonesia sekarang ini banyak yang telah teracuni oleh nilai-nilai ideologi asing, baik ideologi liberalisme-kapitalisme, sosialisme-komunisme, dan aliran keagamaan yang fanatis, militan dan radikal. Kenyataan menunjukkan bahwa sebagian mahasiswa yang memiliki pola pikir dan pola tindak liberalis, kebarat-baratan, kekiri-kirian, dan bahkan mudah terprovokasi oleh paham radikal keagamaan, seperti paham terorisme, fundamentalisme dan gerakan ISIS.

\section{Aspek Politik}


Mahasiswa Indonesia tidak sedikit yang terkotak-kotak oleh kepentingan politik praktis dari elit politik tertentu. Aspirasi yang digelorakan sekarang ini tidak semuanya murni untuk kepentingan rakyat, namun telah banyak yang ditunggangi oleh kepentingan politik yang justru telah merugikan eksistensi pergerakan mahasiswa yang luhur, murni, obyektif seperti pada masa lalu.

\section{Aspek ekonomi,}

Mahasiswa Indonesia tidak jarang yang kurang memiliki daya saing, etos kerja, dan jiwa kewirausahaan. Mahasiswa Indonesia saat ini belum semuanya siap menghadapi kompetisi global, perdagangan bebas, dan pasar bebas. Tidak semua mahasiswa memiliki inovasi, kreasi, terobosan kreatif dalam menghadapi pasar global terutama menghadapi MEA (Masyarakat Ekonomi Asia Tenggara).

\section{Aspek Sosial Budaya,}

Mahasiswa Indonesia tidak sedikit yang berorientasi pada nilai-nilai individualisme, konsumerisme, hedonisme, dan materialisme. Nilai-nilai toleransi, musyawarah mufakat, tenggang rasa, sopan, santun dan ramah telah hilang berganti dengan kekerasan, anarkisme dan kebrutalan yang kadangkala melanggar hukum, seperti tawuran antar pelajar/mahasiswa, penganiayaan, pengrusakan, terlibat narkoba, miras, dan prostitusi. Mahasiswa telah mengalami krisis karakter dan krisis jati diri sehingga perlu dilakukan revolusi mental.

\section{B. Pembahasan}

\section{Nilai-Nilai Revolusi Mental}

Nilai-nilai revolusi mental yang harus ditanamkan kepada mahasiswa sebagai generasi penerus bangsa sebenarnya harus didasarkan pada konsepsi trisaksi yang telah dicetuskan oleh Soekarno dan digelorakan kembali oleh pemerintahan Jokowi-JK. Visi trisakti yang memfokuskan pada tiga pilar harus dihidupkan kembali, dijabarkan kembali, diaplikasikan 
kembali, dan dioperasionalkan kembali sesuai dengan konteks kekinian, khususnya sesuai dengan konteks kemahasiswaan :

\section{Mahasiswa Berdaulat Secara Politik}

Diperlukan nilai-nilai kejuangan, kebangsaan, nasionalisme, patriotisme, dan bela negara yang harus ditanamkan kepada semua mahasiswa Indonesia agar supaya menjadi benteng dan filter dalam menghadapi nilai-nilai global yang berasal dari nilai-nilai asing, seperti liberalisme-kapitalisme, sosialisme-komunisme, dan nilai-nilai fanatisme-radikalismefundamentalisme agama. Melalui bingkai persatuan, kesatuan, dan keutuhan bangsa, maka mahasiswa tidak akan mudah terkotak-kotak oleh kepentingan politik elit dalam politik praktis. Hal ini dilakukan untuk menjaga, memelihara, dan mengamankan keyakinan mahasiswa yang berdaulat dengan memegang teguh empat pilar kebangsaan (Pancasila, UUD1945, Bhineka Tunggal Ika, NKRI)

\section{Mahasiswa Berdikari Secara Ekonomi}

Maknanya, diperlukan nilai-nilai inovasi, kreasi, dan invensi (penemuan baru) yang harus ditanamkan kepada semua mahasiswa Indonesia agar supaya memiliki daya saing, etos kerja, dan jiwa kewirausahaan bangsa untuk menyiapkan sumber daya manusia yang berkualitas dan unggul sehingga akan dapat memacu pertumbuhan ekonomi, kesejahteraan masyarakat, dan pembangunan nasional di tengah tantangan pasar bebas dan perdagangan bebas. Penyiapan sumber daya manusia yang inovatif, kreatif dan enterprenuership akan menciptakan mahasiswa yang berdikari.

\section{Mahasiswa Berkeperibadian Secara Budaya.}

Diperlukan nilai-nilai toleransi, gotong royong, tenggang rasa, humanis, protagonis, sopan, santun, dan simpatik yang harus ditanamkan kepada semua mahasiswa Indonesia agar supaya memiliki jiwa, hati, mental, karakter, dan moral yang baik, benar, unggul, manusiawi, beradab dan bermartabat sehingga akan mampu membentengi jati diri dan identitas bangsa dari ancaman invidualisme, liberalisme, materialisme, hedonisme, dan konsumerisme. Penyiapan pola pikir, dan cara pandang yang berbasis pada nilai-nilai kearifan lokal yang dibingkai dalam semangat, rasa dan paham kebangsaan akan mampu membentuk mahasiswa yang berkepribadian. 


\section{Strategi Menanamkan Revolusi Mental Kepada Mahasiswa}

Dalam diskusi Focus Group Discusion dijelaskan bahwa:

Strategi menanamkan nilai-nilai revolusi mental kepada mahasiswa harus dilakukan secara sistematis, logis, dialogis, dan interaktif, dimulai dari calon mahasiswa, mahasiswa, saat menjadi mahasiswa, dan setelah menjadi mahasiswa. Penanaman nilai-nilai revolusi mental pada mahasiswa yakni saat mengikuti Orientasi Pengenalan Kampus (Ospek), (Subagyo, 2015).

Calon mahasiswa telah berada di perguruan tinggi, diberikan semacam penataran wawasan kebangsaan dan bela negara yang waktunya cukup memadai, misalnya dua hari untuk melakukan pemahaman/penghayatan/penjiwaan wawasan kebangsaan. Penanaman nilai-nilai revolusi mental saat mahasiswa mengikuti mata kuliah pendidikan kewarganegaraan. Dalam mata kuliah dasar umum ini, setiap mahasiswa harus dibekali dengan nilai-nilai wawasan kebangsaan yang disesuaikan dengan menyusun Silabus dan dan Satuan acara perkuliahan Pendidikan kewarganegaraan yang mengarahkan nilai-nilai revolusi mental untuk meningkatkan wawasan kebangsaan. Para dosen di kampus memegang peran penting dalam menanamkan nilainilai revolusi mental secara nyata, kongkret, operasional, dengan bahasa lugas, dan mudah dicerna oleh mahasiswa sehingga tidak membosankan, karena selama ini mahasiswa bosan dengan dengan mata kuliah pendidikan kewarganegaraan yang diajarkan oleh dosen secara monoton, dan berisfat satu arah.

Penanaman nilai-nilai revolusi mental setelah mahasiswa selesai melaksanakan perkuliahan dan ujian skripsi sehingga tinggal menunggu wisuda. Sebelum mahasiswa melaksanakan prosesi wisuda maka diperlukan waktu satu hari untuk menanamkan nilai-nilai revolusi mental yang berbasis pada wawasan kebangsaan berupa pembekalan, sosialisasi maupun pelatihan wawasan kebangsaan, sehingga akan menjadi bekal bagi para mahasiswa/calon wisudawan untuk terjun ke tengah masyarakat dan di dunia kerjanya masing-masing. 
Harapannya, para mahasiswa mampu menerapkan nilai-nilai revolusi mental dapat diri sendiri, keluarga, masyarakat dan lingkungan kerjanya masing-masing ke depannya nanti.

\section{Hal-hal yang dibutuhkan Untuk Penanaman Nilai-Nilai Revolusi Mental}

\section{Mahasiswa}

Terdapat beberapa kesiapan yang dibutuhkan untuk melakukan penanaman nilai-nilai revolusi mental kepada mahasiswa yang harus terpenuhi agar supaya program ini berjalan dengan lancar, antara lain:

a. Kesiapan Instrumental. Dalam kaitan ini, dibutuhkan payung hukum, landasan yuridis dan aturan hukum yang jelas, kongkret dan kuat dalam memayungi proses penanaman revolusi mental kepada para mahasiswa berupa penyusunan, pembahasan dan pengesahan UU Komponen Cadangan, UU Komponen Pendukung, UU Bela Negara, UU Wawasan Nusantara, maupun berbagai aturan perundang-undangan lain yang terkait. Hal ini penting dibuat agar supaya terdapat pedoman, pegangan, dan koridor dalam melakukan sosialisasi, internalisasi, dan pelatihan nilai-nilai revolusi mental mahasiswa.

b. Kesiapan Struktural. Dalam kaitan ini, dibutuhkan kelembagaan yang permanen, absah, dan ada di tingkat pusat dan daerah berupa Badan Penanaman Wawasan Kebangsaan dan Bela Negara (BPWKBN) di pusat maupun di daerah (Propinsi, Kabupaten/Kota) yang memiliki tugas, fungsi dan kewenangan menyelenggarakan pembinaan, sosialisasi, koordinasi, supervisi, evaluasi, pengawasan, dan pengendalian penanaman nilai-nilai revolusi mental guna membentuk karakter mahasiswa yang berwawasan kebangsaan dan berkesadaran bela negara. Badan ini merupakan badan negara yang bersifat nasional dan bersumber anggaran pemerintah yakni dari APBN.

c. Kesiapan Kultural. Dalam kaitan ini, dibutuhkan persepsi, pandangan, dan sikap masyarakat, kelompok masyarakat, ormas, LSM dan semua komponen bangsa yang positif, mendukung dan membantu ide, gagasan, dan program penanaman nilai-nilai revolusi mental di kalangan mahasiswa. Semua pihak, khususnya dunia pendidikan di kampus dan di kalangan mahasiswa harus menilai bahwa program ini sangat baik dan bermanfaat bagi pengembangan sumber daya manusia Indonesia mengingat mahasisw merupakan generasi penerus bangsa 
dan aset insani bangsa yang tidak ternilai dengan apapun sehingga harus digodok, digembleng, dididik, dilatih dan dibina melalui revolusi mental sehingga berwawasan kebangsaan dan berkesadaran bela negara. Cara pandang lama yang menyatakan bahwa penanaman wawasan kebangsaan dan bela negara sebagai upaya untuk militer masuk politik harus dikikis dan dibuang jauh-jauh karena jaman telah berubah dan terdapat keharmonisan yang erat, solid, dan kokoh antara sipil dan militer. Program ini merupakan murni untuk kepentingan bangsa dan negara, tanpa ada pretensi politik praktis.

Bentuk upaya kesadaran Bela Negara di kalangan Mahasiswa

\section{Terbentuknya Resimen Mahasiswa (Menwa)}

Untuk merealisasikan UU Nomor 29 Tahun 1954, diselenggarakan Wajib Latih di kalangan mahasiswa dengan pilot proyek di Bandung pada tanggal 13 Juni 1959-14 September 1959, yang kemudian dikenal dengan WALA 59 (Wajib Latih tahun 1959). WALA 59 merupakan batalyon inti mahasiswa yang merupakan cikal bakal Resimen Mahasiswa sekarang ini. Kemudian disusul Batalyon 17 Mei di Kalimantan Selatan. Mahasiswa yang memperoleh latihan ini siap mempertahankan home-front dan bila perlu ikut memanggul senapan medan laga. Mahasiswa Wajib Latih ini dididik di Kodam VI/Siliwangi dan para mahasiswa ini diberi hak untuk mengenakan lambang Siliwangi.

Bermula dari itulah, pada masa demokrasi terpimpin dengan politik konfrontasi dalam hubungan luar negeri, telah menggugah semangat patriotisme dan kebangsaan mahasiswa untuk mengabdi kepada nusa dan bangsa sebagai sukarelawan. Penyelenggaraan pendidikan dan latihan kemiliteran selanjutnya dilaksanakan untuk mempersiapkan mahasiswa sebagai potensi pertahanan dan keamanan negara melalui Rinwa (Resimen Induk Mahasiswa), yang selanjutnya namanya berubah menjadi Menwa (Resimen Mahasiswa). Tujuan dan Tugas Pokok Resimen Mahasiswa adalah sebagai berikut.

Tujuan Resimen Mahasiswa Indonesia adalah:

1. Mempersiapkan mahasiswa yang memiliki pengetahuan, sikap disiplin, fisik dan mental serta berwawasan kebangsaan agar mampu melaksanakan tugas Tri Dharma Perguruan Tinggi dan menanamkan dasar-dasar kepemimpinan dengan tetap mengacu pada tujuan pendidikan nasional. 
2. Sebagai wadah penyaluran potensi mahasiswa dalam rangka mewujudkan hak dan kewajiban warga Negara dalam Bela Negara.

3. Mempersiapkan potensi mahasiswa sebagai bagian dari potensi rakyat dalam Sistem Pertahanan Rakyat Semesta.

Tugas pokok Resimen Mahasiswa Indonesia meliputi:

a. Merencanakan, mempersiapkan dan menyusun seluruh potensi mahasiswa untuk memantapkan ketahanan nasional, dengan melaksanakan usaha dan atau kegiatan bela negara.

b. Membantu terwujudnya penyelenggaraan fungsi perlindungan masyarakat (LINMAS), khususnya Penanggulangan Bencana dan Pengungsi (PBP)

c. Membantu terlaksananya kesadaran bela negara dan wawasan kebangsaan dalam organisasi kepemudaan.

\section{Kesimpulan}

Penanaman sikap revolusi mental melalui pembelajaran pendidikan kewarganegaraan menjadi titik acuan terbentuknya keberhasilan pembangunan bangsa menuju bangsa yang berkarakter, bermoral, dan berbudaya. Oleh sebab itu, untuk merealisasikan program yang dijadikan konsep baru pemerintahan diperlukan berbagai sektor antara lain sektor pendidikan, agama dan humanisme, sosial, dan ekonomi. Keempat sektor tersebut, memiliki penguatan strategi yang mana sektor pendidikan sangat mendukung terbentuknya mahasiswa Indonesia dalam menamkan karakter dan moralitas yang tinggi dalam menjunjung nilai-nilai kebudayaan. Sektor agama dan humanisme sebagai penyeimbang dan pengendali, maka segala hal yang bersifat tidak baik dapat terluruskan kembali. Sektor sosial menjadi pokok utama yang mana dalam proses kehidupan pasti akan bergantung dengan yang lain sebagai rasa kesosialan dengan saling gotong royong, dan kepedulian antara sesama. Ekonomi dijadikan penentu bagi kesejahteraan rakyat. Selain itu penanaman revolusi mental akan memberi kesadaran pada masyarakat akan besarnya harapan menuju bangsa yang berdaulat, mandiri, dan berkepribadian dengan menanamkan nilai kesadar masyarakat akan pentingnya kejayaan bangsa dalam menopang kemerosotan karakter bangsa. 


\section{DAFTAR PUSTAKA}

Busroh, Abu Daud \& Abubakar Busro.1993. Ilmu Negara. Jakarta. Bumi Aksara.

Effendi, Taufiq, 2008, Menteri Pendayagunaan Aparatur Negara pada Seminar Pembangunan Sumber Daya Manusia Aparatur Negara, Makalah, Universitas Diponegoro, Semarang.

Erwin, Muhamad, 2011. Pendidikan Kewarganegaraan Republik Indonesia. Bandung. Refika Aditama.

Koentjaraningrat. 2003. Pengantar Antropologi I. Jakarta: Rineka Cipta

Mulyasa. 2015. Revolusi Mental dalam Pendidikan. Rosdakarya.

Setio Budi,1997: Jurnal Perencanaan Pembangunan, Nomor 17, Oktober.

Sugiyono. 2006. Metode Penelitian Kuantitatif, Kualitatif dan R\&D. Bandung: Alfabeta.

Sumarsono, dkk. 2005. Pendidikan Kewarganegaraan. Jakarta. PT. Gramedia Pustaka Utama.

2015. Sosialisasi Gerakan Revolusi Mental. Jakarta. Kementerian Koordinator Bidang Pembangunan Manusia dan Kebudayaan.

Subagyo, Agus, 2015. Makalah FGD : Penanaman nilai-nilai revolusi mental bagi generasi muda khususnya calon mahasiswa untuk membentuk generasi muda yang berwawasan kebangsaan dan berkesadaran bela negara. 
revolusimental.go.id

http://nasional.sindonews.com

pemerintah.net/uu-asn-aparatur-sipil-negara

http://www.rayakultura.net/pendidikan-dalam-strategi-kebudayaan 